\title{
Crystallization and Second-Order Transitions in Silicone Rubbers
}

\author{
By C. E. Weir, W. H. Leser, and L. A. Wood
}

\begin{abstract}
In the course of an investigation to determine which rubbers might be suitable for use at low temperatures, interferometric measurements of the length-temperature relationships of silicone rubbers have been made. Crystallization was found between $-60^{\circ}$ and $-67^{\circ} \mathrm{C}$ in Dow-Corning Silastic X-6160 and in General Electric 9979G silicone rubber, the latter of which contains no filler. Crystallization between $-75^{\circ}$ and $-85^{\circ} \mathrm{C}$ was found in Silastic 250. Melting occurred over a range of temperature above the temperature of crystallization. The volume change on crystallization varied from 2.0 to 7.8 percent. No crystallization or melting phenomena were observed in Silastic $\mathrm{X}-6073$ between $-180^{\circ}$ and $+100^{\circ} \mathrm{C}$. All types of silicone rubber exhibited a second-order transition at about $-123^{\circ} \mathrm{C}$, the lowest temperature at which such a transition has been observed in a polymer. The coefficient of linear thermal expansion of silicone rubbers containing no filler was found to be about $40 \times 10^{-5} / \mathrm{deg} \mathrm{C}$ between $-35^{\circ}$ and $0^{\circ} \mathrm{C}$.
\end{abstract}

\section{Introduction}

Most of the properties of the silicone rubbers (polysiloxanes), developed especially for use at high temperatures, have been found to show less change with temperature than those of other polymers $[1,6] .^{2}$ Recently there has been particular interest in the properties of all types of rubbers at low temperatures. Consequently the behavior of the silicone rubbers at low temperatures has taken on additional importance.

The fundamental phenomena related to the stiffening of rubbers at low temperatures are the second-order transition [4] and crystallization [8]. Both of these phenomena influence the relationship between the dimensions of a specimen and the temperature. In the present investigation the change of length at different temperatures was measured with an interferometer.

\section{Materials Investigated}

The samples of silicone rubber were of commercial origin. Two of them contained no fillers or

\footnotetext{
1 The work reported here was supported by the Office of Naval Research

1 The work reported here was supported by the Office of Naval Research
and the Office of The Quartermaster General as part of Project ONR (QMC) NR-033-314.

${ }^{2}$ Figures in brackets indicate the literature references at the end of this paper.
} Transitions of Silicone Rubbers vulcanizing agents and were highly elastic brown solids of low strength. They transmitted light relatively well aud had refractive indices of 1.4028 and 1.4040 , respectively. The densities measured by the method of hydrostatic weighing were found to be 0.973 and $0.974 \mathrm{~g} / \mathrm{cm}^{3}$ at $25^{\circ} \mathrm{C}$, respectively. These densities appear to be slightly higher than densities of liquid silicones previously reported $[2,5]$. These samples were produced by the General Electric Co. and were supplied through the kind cooperation of the Connecticut Hard Rubber Co. They are designated General Electric 9979G silicone rubber and in this paper are referred to as gum silicones for convenience.

The other samples of silicone rubber contained filler and were vulcanized. These were obtained through the cooperation of the Dow-Corning Co. and were designated Silastic X-6073 and Silastic $\mathrm{X}-6160$. These types were especially designed for use at low temperatures. Silastic X-6160 is described as differing only slightly from Silastic 160 , which has been reported [6] to contain 60 percent of filler consisting of equal weights of zinc oxide and titanium dioxide. No data are available on the other varieties of Silastic.

A vulcanizate of Silastic 250 , a new variety of silicone rubber, was also furnished by the DowCorning Co. 


\section{Experimental Method}

The interferometer arrangement described by Wood, Bekkedahl, and Peters [10] was used, with minor modifications, to determine the thickness of rubber specimens as a function of temperature. The apparatus was modified by surrounding the lower removable portion of the interferometer container with close-wound, close-fitting helix of 1/8-in. copper tubing. The lower end of the helix was terminated in a wye, one leg of which was terminated in a fine orifice. The other leg of the wye passed through the wall of the container and was terminated in a somewhat larger orifice. Dry carbon-dioxide-free air was used to eliminate clogging of lines by freezing of vapors. This air flowed into the upper end of the helix at a pressure of $1 \mathrm{~cm}$ of mercury, circulated through the coil, and was discharged into both the surrounding Dewar and the interferometer chamber. Internal and external stirring and a markedly lower temperature gradient resulted from the use of this air stream. After the air had passed through the interferometer chamber it was discharged across the top glass plate of the container, thereby effectively eliminating condensation of moisture on this plate. Liquid nitrogen, used as a coolant, produced temperatures as low as $-196^{\circ} \mathrm{C}$. The cooling was effected in a manner similar to that described previously [10].

The light source consisted of a helium discharge tube. Essentially monochromatic light of wavelength 5,876 A was obtained by use of appropriate filters.

The top interferometer plate, a semicircular disk of fused quartz $2 \mathrm{~cm}$ in diameter and $2 \mathrm{~mm}$ thick, which was supported by the test specimens, weighed $0.82 \mathrm{~g}$.

No correction for change in refractive index of air with temperature was applied to the data obtained.

Slabs of silicone rubber were accurately cut with parallel faces by means of a sharp blade and a small miter box. One to three specimens, generally 4-mm cubes, cut from a slab were placed between the two interferometer plates with the parallel faces of the specimens in contact with the plates. After removing the eyepiece of the telescope, the elastic specimens were moved about between the interferometer plates until the images of the slit reflected from the upper and lower plates appeared to coincide. Fringes of the desired width were clearly visible when the eyepiece of the telescope was replaced.

Measurements below temperatures at which rubbers crystallized presented two main difficulties: maintaining visible fringes during the dimensional changes occurring on freezing; and maintaining a uniform rate of cooling at low temperatures.

Attempts were made to obtain fringes with crystalline material by cooling the specimens by immersion in liquid nitrogen and then manipulating the frozen specimens with suitable prods so as to produce fringes. These attempts were unsuccessful principally because of frosting of all exposed surfaces, and therefore measurements were made below $-100^{\circ} \mathrm{C}$ only in a few fortuitous experiments in which fringes were maintained during crystallization.

Measurements of expansion were found to be difficult to obtain on cooling at very low temperatures, since the height of the liquid nitrogen in the surrounding Dewar was necessarily such that intermittent contact occurred between the coolant and the exterior of the interferometer container. Such contact produced rapid and nonuniform cooling. A rate of cooling or heating of about 1 deg $\mathrm{C}$ per minute was considered desirable in these experiments [10]. Most measurements at low temperatures were made on heating and were carried out by cooling the interferometer to $-196^{\circ} \mathrm{C}$, insulating the system, and permitting it to warm by absorption of heat from the surroundings.

\section{Results and Discussion}

Graphical results shown in the succeeding figures are typical but do not include measurements on all specimens of silicone rubber investigated. In most instances only those portions of the curves are shown that are considered pertinent to the discussion.

Crystallization on cooling to low temperatures, manifested as a radical decrease in specimen length on cooling over a narrow temperature interval, was observed in all samples except Silastic X-6073. Melting, observed as the reverse process on heating, was found above the crystallization temperature in all samples except $\mathrm{X}-6073$.

Expansion curves on cooling and heating a gum silicone are shown in figure 1. Crystallization is believed to occur between $-60^{\circ}$ and $-67^{\circ} \mathrm{C}$. 


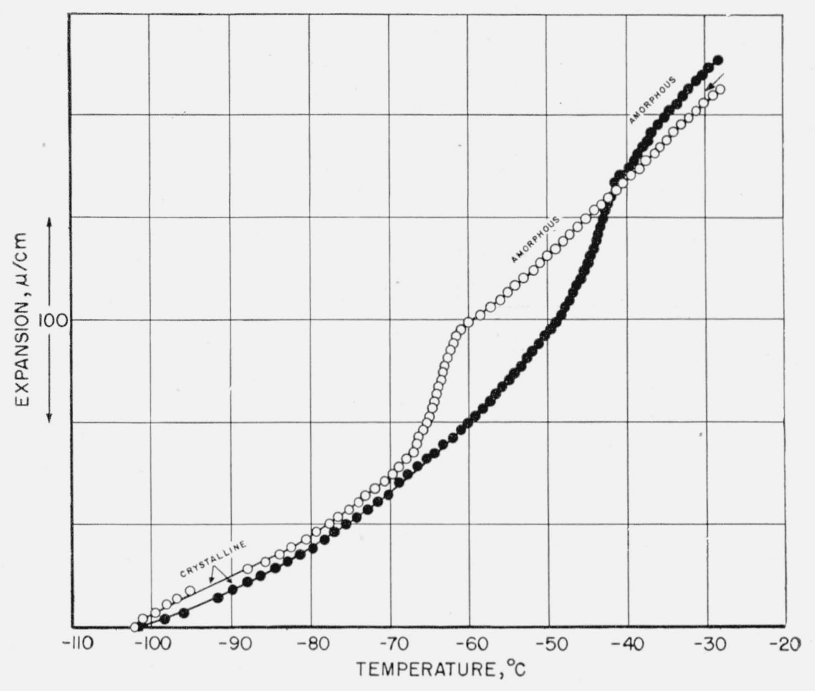

FiguRE 1. Crystallization and melting of gum silicone.

Average thickness at $20^{\circ} \mathrm{C}, 0.414 \mathrm{~cm}$. Values for expansion are calculated in terms of the thickness at $20^{\circ} \mathrm{C}$. $\bigcirc$, Observations on cooling; $\boldsymbol{\theta}$, observations on heating.

This temperature range of crystallization was found in the gum silicones and Silastic X-6160 (fig. 5). Results obtained with Silastics X-6073 and 250 are somewhat different and will be described in detail later. The crystallization depicted by figure 1 appears to be a rapid process in contrast to the crystallization of natural rubber studied by Bekkedahl and Wood [3, 9]. Attempts to vary the temperature at which crystallization occurred or to produce supercooled material by rapidly chilling the interferometer in a liquid nitrogen bath were not successful, as specimens invariably crystallized near $-60^{\circ} \mathrm{C}$. The values for hardness of several varieties of Silastic at temperatures as low as $-62^{\circ} \mathrm{C}$ are reported by Konkle, Selfridge, and Servais [6]. All of the values show a rapid rise at the lowest temperature measured. They found that the equilibrium hardness values at temperatures below $-55^{\circ} \mathrm{C}$ were not attained until after $3 \frac{1}{2} \mathrm{hrs}$. Both of these observations are indicative of the crystallization reported in the present paper.

The onset of melting with increasing temperature is not sharp. It is believed that melting begins a few degrees above the crystallization temperature and is complete at about $-39^{\circ} \mathrm{C}$.

The magnitude of the volume change associated with crystallization of gum silicones appears to be variable and as calculated from linear changes ranges from 2.0 to 7.8 percent. The maximum volume change on crystallization of natural rubber has been found to be slightly over 3 percent [8].

If specimens of gum silicone are alternately cooled and heated cyclically at temperatures somewhat above $-60^{\circ} \mathrm{C}$, no evidence of crystallization or melting is observed. Experiments of this nature, carried out between $-30^{\circ}$ and $-50^{\circ} \mathrm{C}$ gave the results shown in figure 2 . If crystallization occurred at a measurable rate in this temperature interval, the length of the specimen would gradually decrease as a function of time. Consequently, the expansion curves on successive heating or cooling would be displaced in the direction corresponding to a smaller length of specimen. The behavior of the gum silicones is in contrast to that of natural rubber, which undergoes slow crystallization at temperatures higher than the optimum crystallization temperature $[8,9]$.

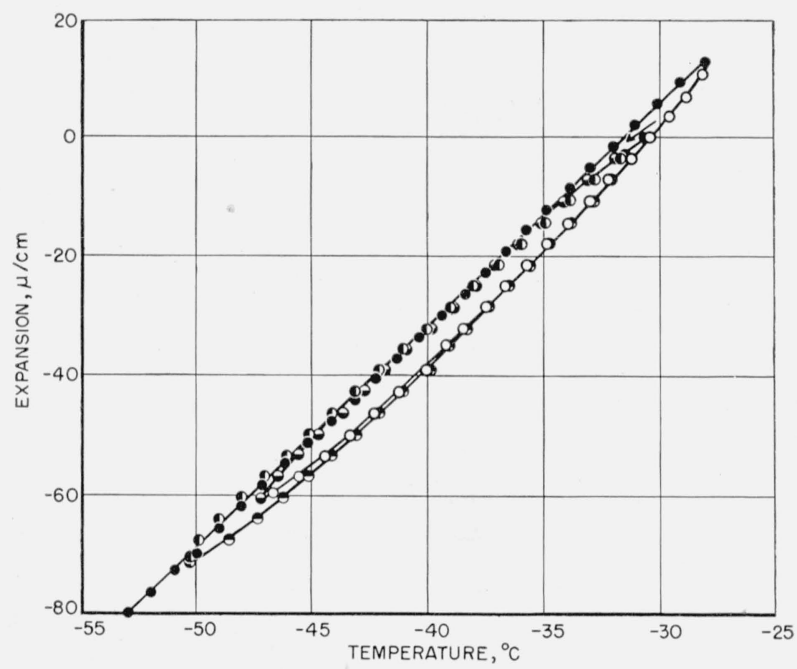

Figure 2. Behavior of gum silicone above the crystallization temperature.

Average thickness of $20^{\circ} \mathrm{C}, 0.414 \mathrm{~cm}$. Values for expansion are calculated in terms of the thickness at $20^{\circ} \mathrm{C}$. O Observations on first cooling; $\boldsymbol{\theta}$, observations on first heating; $\bullet$, observations on second cooling; $\bigcirc$, observations on second heating; observations on third cooling.

The results of expansion measurements of the gum silicones at temperatures far below the crystallization temperature are shown in figure 3. The second-order transition temperature is located as the point of change of slope and is fairly well defined in all curves. The temperatures of the transitions, defined as the intersections of the extrapolated linear segments, are in good agreement on repeated runs. Curvature near the transition temperature produces obvious difficulties in draw- 
ing the linear segments. Differences as large as $5^{\circ} \mathrm{C}$ in transition temperatures as indicated by intersections of projected linear segments have been observed between the curves obtained by heating and cooling at the rate of $1^{\circ} \mathrm{C}$ per minute. From consideration of these factors it appears that the second-order transition of silicone rubbers may be set at $-123^{\circ} \mathrm{C}$ with a maximum estimated uncertainty of $\pm 5^{\circ} \mathrm{C}$. As far as can be ascertained, this represents the lowest second-order transition temperature yet reported for any polymer.

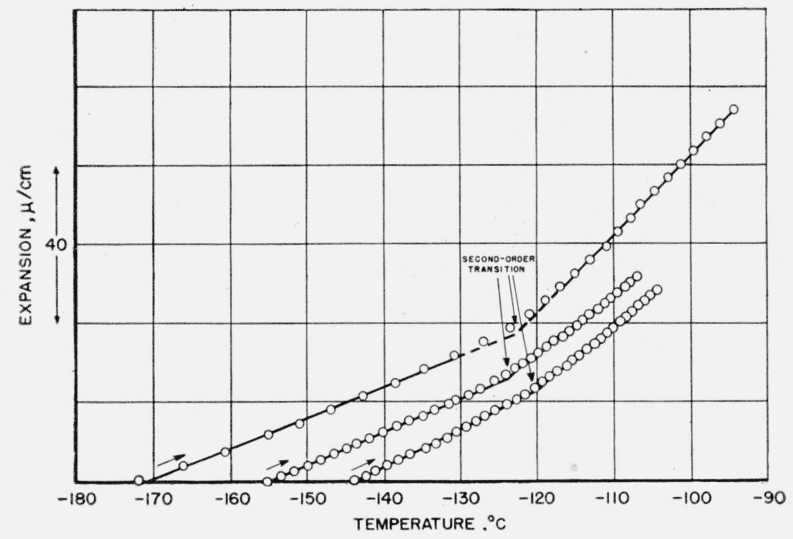

Figure 3. Second-order transitions of GE $9979 \mathrm{G} \mathrm{gum}$ silicone.

Average thickness at $20^{\circ} \mathrm{C}, 0.424 \mathrm{~cm}$. Curves plotted from different origins. Values for expansion are calculated in terms of the thickness at $20^{\circ} \mathrm{C}$.

The transition temperature of $-123^{\circ} \mathrm{C}$ appears to be unaffected by the addition of filler or by vulcanization. This behavior differs from that of natural rubber [4] in which filler and vulcanization change the transition temperature.

Silastic 250 differed from the other silicones in its temperature of crystallization, which was appreciably lower, and in the fact that it could be supercooled, with only partial crystallization. The results of expansion measurements obtained on this variety of silicone rubber are shown in figure 4 .

Observations on heating and cooling shown in figure 4 were obtained separately. It is noted that while a normal second-order transition temperature of $-121^{\circ} \mathrm{C}$ is obtained, crystallization on cooling and completion of melting on heating occur at lower temperatures than previously described. Crystallization on cooling occurs at approximately $-75^{\circ} \mathrm{C}$ and completion of melting on heating at approximately $-45^{\circ} \mathrm{C}$.

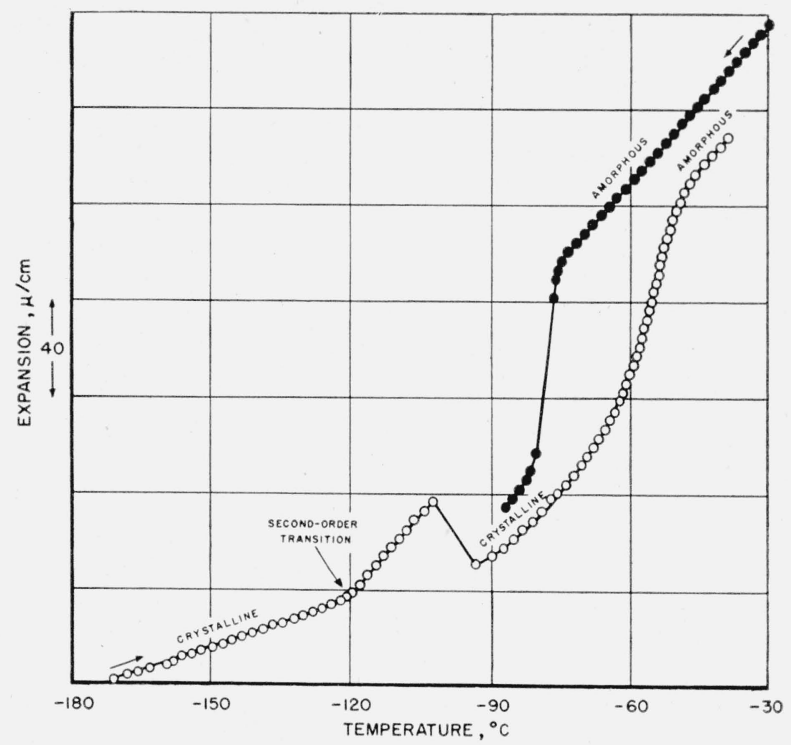

Figure 4. Expansion curves of Silastic 250.

A verage thickness of specimens at $20^{\circ} \mathrm{C}, 0.386 \mathrm{~cm}$. Curves plotted from different origins. Values for expansion are calculated in terms of the thickness at $20^{\circ} \mathrm{C} . \bigcirc$, Observations on heating; $\bullet$, observations on cooling.

There is evidently a range of temperature favorable for crystallization extending from $-75^{\circ}$ to about $-100^{\circ} \mathrm{C}$, since crystallization of supercooled material was observed at the latter temperature on increasing temperature. This behavior is very similar to that of natural rubber $[8,9]$, which can be crystallized over a range of temperatures and which can be supercooled.

Silastic X-6073 differed from the other silicone rubbers in that it showed no evidence whatever of crystallization or melting between $-180^{\circ}$ and $0^{\circ} \mathrm{C}$. A portion of the results of expansion measurements obtained with this variety together with those for Silastic $\mathrm{X}-6160$, which are included for comparison are given in figure 5 .

$\mathrm{X}-6073$ shows no evidence of crystallization or melting at any temperature shown. Additional observations on heating this specimen were extended to $+100^{\circ} \mathrm{C}$ (not shown in fig. 5) with no evidence of crystallization or melting or other transition evidenced by change of slope. The marked linearity shown when crystallization is absent is contrasted with the curvature existing in measurements of expansion on $\mathrm{X}-6160$ below the crystallization range. This result may indicate that the amount of crystalline material is varying with consequent curvature of the graphs, over a considerable range of temperature.

The change in rate of expansion at the second- 
order transition is greater for $\mathrm{X}-6073$ than for $\mathrm{X}-6160$, and the transition occurs at a slightly higher temperature.

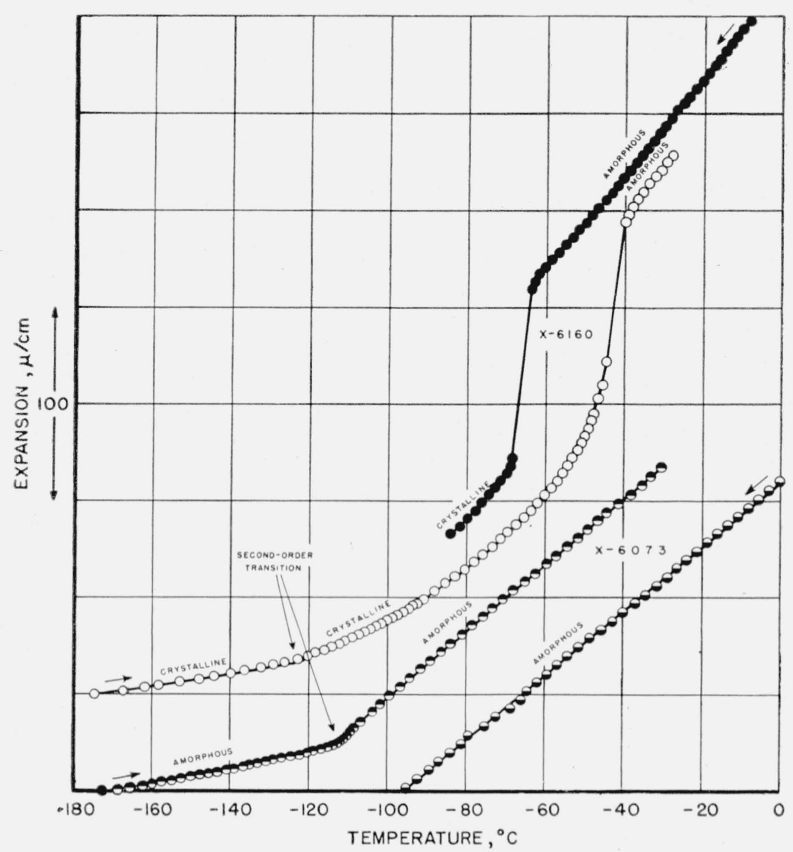

Frgure 5. Expansion curves of Silastics $X-6073$ and $X-6160$.

Curves plotted from different origins. Values for expansion are calculated in terms of the thickness at $20^{\circ} \mathrm{C}$. Silastic $\mathrm{X}-6073$ : average thickness at $20^{\circ} \mathrm{C}, 0.326 \mathrm{~cm}$; $\odot$, observations on heating; $\ominus$, observations on cooling. Silastic X-6160: average thickness at $20^{\circ} \mathrm{C}, 0.385 \mathrm{~cm} ; \bigcirc$, observations on heating; observations on cooling.

The data obtained have been used to calculate coefficients of linear expansion of silicone rubbers.
It is to be emphasized that there is some doubt concerning the reliability of the results, since no special precautions were taken to avoid possible tilting of the specimens as discussed by Saunders [7], and because the slopes of expansion curves were obtained graphically from single runs in most instances. The coefficients of expansion are given in table 1 .

It will be noted that the gum silicones have very high coefficients of expansion. The coefficient of cubical expansion of such isotropic material would be about $120 \times 10^{-5}$ per deg $\mathrm{C}$ between $-35^{\circ}$ and $0^{\circ} \mathrm{C}$, which is as large as that of many organic liquids.

The coefficients of expansion of the other silicone rubbers are lower, as expected from the fact that they all contain fillers that reduce the coefficients. The coefficients of these rubbers observed below the second-order transition temperature are approximately 15 to 35 percent of the corresponding values above the transition.

\section{Summary}

This investigation has revealed a second-order transition in all silicone rubbers examined at a temperature of approximately $-123^{\circ} \mathrm{C}$. As far as can be ascertained this is the lowest temperature at which a second-order transition has been observed in a polymer. In one variety of silicone rubber ( $\mathrm{X}-6073)$ no crystallization or melting was observed between $-180^{\circ}$ and $+100^{\circ} \mathrm{C}$; in the other varieties, crystallization and melting phenomena were observed at low temperatures.

TABLE 1. Coefflcients of linear thermal expansion of silicone rubbers

\begin{tabular}{|c|c|c|c|c|c|}
\hline \multirow[b]{2}{*}{ Silicone rubber } & \multirow[b]{2}{*}{ Temperature range } & \multirow[b]{2}{*}{ Heating or cooling } & \multicolumn{3}{|c|}{ Coefficients of expansion per degree $\mathrm{C}$} \\
\hline & & & $\begin{array}{l}\text { Below } \\
\text { second- } \\
\text { order } \\
\text { transition }\end{array}$ & $\begin{array}{l}\text { Immediacely } \\
\text { above } \\
\text { second-order } \\
\text { transition }\end{array}$ & $\begin{array}{l}\text { Above cry- } \\
\text { stallization } \\
\text { or melting } \\
\text { range }\end{array}$ \\
\hline \multirow[b]{2}{*}{ G. E. $9979 \mathrm{G}$ gum silicone $n=1.4040 \ldots$} & ${ }^{\circ} \mathrm{C}$ & & & & \\
\hline & -35 to 0 & Heating ..... & & & $39 \times 10^{-5}$ \\
\hline \multirow{3}{*}{ G. E. 9979 G gum silicone $n=1.4028 \ldots \ldots$} & -120 to -100 & do & & $18 \times 10^{-5}$ & \\
\hline & -180 to -125 & .... do . ..... & $9 \times 10^{-5}$ & & \\
\hline & 0 to $-75 \ldots \ldots$ & Cooling .... & & & 22 \\
\hline \multirow[t]{3}{*}{ Silastic 250} & -120 to $-102 \ldots$ & Heating ............. & & 25 & \\
\hline & -180 to -120 & .... do . . ....... & 7 & & \\
\hline & 0 to -95 & Cooling ........... & & 16 & - \\
\hline \multirow[t]{3}{*}{ Silastic $\mathrm{X}-6073 \ldots$} & -116 to +100 & Heating ............ & . & 17 & ....... \\
\hline & -180 to -116 & ..... do _..... & 3 & & $-\ldots$ \\
\hline & $\begin{array}{l}0 \text { to }-65 \\
-35 \text { to } 0\end{array}$ & $\begin{array}{l}\text { Cooling } \\
\text { Heating }\end{array}$ & & & $\begin{array}{l}24 \\
25\end{array}$ \\
\hline Silastic X-6160_. & -120 to -90 & do & . & 11 & \\
\hline & -180 to -120 & _._. do _ _ _ _ _ n & 4 & & \\
\hline
\end{tabular}




\section{References}

[1] S. L. Bass, Silicone rubber-A new synthetic elastomer, Proceedings of Second Rubber Technology Conference, London, Paper No. 22, p. 17 (1948).

[2] O. K. Bates, Thermal conductivity of liquid silicones, Ind. Eng. Chem. 41, 1966 (1949).

[3] N. Bekkedahl, Forms of rubber as indicated by the temperature-volume relationship, J. Research NBS 13, 411 (1934) RP717.

[4] R. F. Boyer and R. S. Spencer, Second-order transition effects in rubber and other high polymers, Advances in Colloid Sci. II, chapter I, H. Mark and G. S. Whitby (Interscience Publishers Inc., New York, N. Y., 1946).

[5] M. J. Hunter, E. L. Warrick, J. F. Hyde, and C. C. Curie, Organosilicon polymers II-the open chain dimethylsiloxanes with trimethylsiloxy end groups, J. Am. Chem. Soc. 68, 2284 (1946).

[6] G. M. Konkle, R. R. Selfridge, and P. C. Servais,
Behavior of silastic on aging, Ind. Eng. Chem. 39, 1410 (1947).

[7] J. B. Saunders, Improved interferometric procedure with application to expansion measurements, J. Research NBS 23, 179 (1939) RP1227.

[8] L. A. Wood, Crystallization phenomena in natural and synthetic rubbers, Advances in Colloid Sci. II, chapter II, H. Mark and G. S. Whitby (Interscience Publishers Inc., New York, N. Y., 1946.

[9] L. A. Wood and N. Bekkedahl, Crystallization of unvulcanized rubber at different temperatures, J. Research NBS 36, 489 (1946). RP1718. J. Applied Physics 1\%, 362 (1946).

[10] L. A. Wood, N. Bekkedahl, and C. G. Peters, Application of the interferometer to the measurement of dimensional changes in rubber, J. Research NBS 23, 571 (1939) RP1253.

Washington, September 13, 1949. 